\title{
Bilateral transversus abdominus plane block for incisional hernia repair
}

\author{
Yavuz GÜRKAN, ${ }^{1}$ Murat TEKIN, ${ }^{1}$ Ahmet Oktay YiRMIBEŞOĞLU, ${ }^{2}$ Emine AYSU SALViZ ${ }^{3}$
}

To the Editor,

The transversus abdominus plane (TAP) block is a relatively new described regional anesthesia technique at the triangle of Petit, ${ }^{[1]}$ in order to block a number of abdominal wall nerves hence providing widespread analgesia. More recently, ultrasound guided TAP block has been described with promises of better localization and deposition of the local anaesthetic with improved accuracy. ${ }^{[2]}$ It's good postoperative analgesia effect has been shown several times in a variety of lower abdominal procedures; ${ }^{[3,4]}$ however there has been controversy in the literature regarding the spread and level of block achieved with a single TAP injection. ${ }^{[5,6]}$

We would like to present a 62-year-old female, ASA physical status III patient with cirrhosis, cardiac failure, hypertension and diabetes mellitus, who underwent an incisional hernia repair. The patient had also undergone an umbilical hernia repair 2 months ago. Ultrasound guided TAP block was performed bilaterally as an anesthesia procedure. The block was performed using a high frequency linear probe (10-18 MHz, Esaote My Lab 30, Genoa, Italy). The block was performed at the mid-axillary line between the costal margin and iliac crest (Figure 1). In plane technique was used and $20 \mathrm{~mL}$ of levobu- pivacaine $0.25 \%$ was applied for each side. For skin incision $5 \mathrm{~mL}$ of lidocaine $2 \%$ was used. In order to provide sedation and analgesia, $50 \mu \mathrm{cg}$ of fentanyl and $1 \mathrm{mg}$ of midazolam IV were administered. After depleting acid fluid and repairing $0.5 \mathrm{~cm}$ fascia defect, the operation was completed in 30 minutes uneventfully. Patient was comfortable during the surgery. The patient was followed for 5 days without any complication.

General anesthesia was not prefered in order to avoid cardiac and hepatic effects of systemic anesthetics. Although coagulation parameters seem to

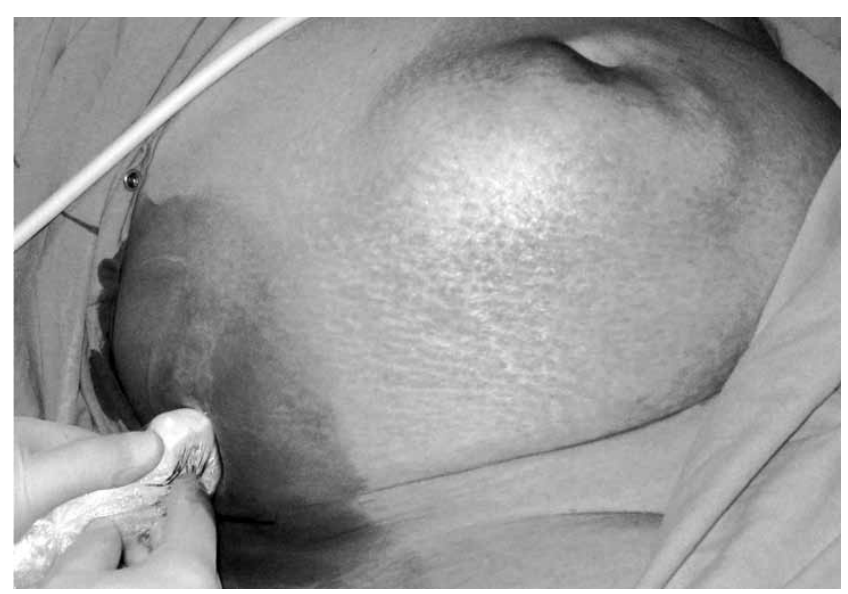

Figure 1. High frequency lineer probe and in-plane technique was used during block performance.

Departments of ${ }^{1}$ Anesthesiology and Reanimation, ${ }^{2}$ General Surgery, Kocaeli University Faculty of Medicine, Kocaeli; 
be normal, spinal anesthesia was not prefered because of low platelet counts $\left(80 \times 10^{3} / \mathrm{U}\right)$.

This is the first case report presenting the use of TAP block for surgical anesthesia. TAP block could be considered as an anesthetic option for similar cases.

\section{References}

1. Rafi AN. Abdominal field block: a new approach via the lumbar triangle. Anaesthesia 2001;56(10):1024-6.

2. Hebbard P, Fujiwara Y, Shibata Y, Royse C. Ultrasound-guided transversus abdominis plane (TAP) block. Anaesth Intensive Care 2007;35(4):616-7.
3. Carney J, McDonnell JG, Ochana A, Bhinder R, Laffey JG. The transversus abdominis plane block provides effective postoperative analgesia in patients undergoing total abdominal hysterectomy. Anesth Analg 2008;107(6):2056-60.

4. Conaghan $P$, Maxwell-Armstrong C, Bedforth N, Gornall C, Baxendale B, Hong LL, Carty HM, Acheson AG. Efficacy of transversus abdominis plane blocks in laparoscopic colorectal resections. Surg Endosc 2010;24(10):2480-4.

5. McDonnell JG, Laffey JG. Transversus abdominis plane block. Anesth Analg 2007;105(3):883.

6. El-Dawlatly AA, Turkistani A, Kettner SC, Machata AM, Delvi $M B$, Thallaj $A$, et al. Ultrasound-guided transversus abdominis plane block: description of a new technique and comparison with conventional systemic analgesia during laparoscopic cholecystectomy. Br J Anaesth 2009;102(6):763-7. 